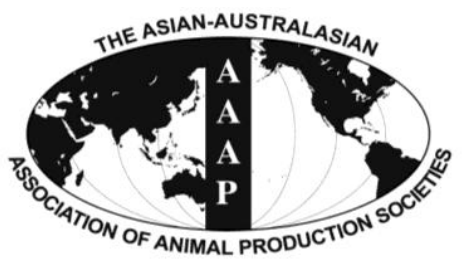

Asian Australas. J. Anim. Sci.

Vol. 26, No. 11 : 1545-1552 November 2013

http://dx.doi.org/10.5713/ajas.2013.13128

www.ajas.info

pISSN 1011-2367 elSSN 1976-5517

\title{
Effects of Trichostatin A on Cumulus Expansion during Mouse Oocyte Maturation
}

\author{
Ming Du, Xiangwei Fu, Yanhua Zhou, and Shien Zhu* \\ Key Laboratory of Animal Genetics, Breeding and Reproduction,Ministry of Agriculture and \\ National Engineering Laboratoryfor Animal Breeding, College of Animal Science and Technology, \\ China Agricultural University, Beijing, China
}

\begin{abstract}
This study was conducted to investigate the effects of Trichostatin A (TSA) on cumulus expansion during mouse oocyte maturation. TSA treatment inhibited cumulus expansion and significantly reduced the cumulus expansion index (CEI) ( $p<0.05)$. To determine the underlying mechanism, the expression levels of several key factors that play crucial roles in cumulus expansion including components of extracellular matrix (ECM) (Has2, Ptgs2, Ptx3, and Tnfaip6) and Growth differentiation factor 9 (GDF9) were measured in control and TSA treated samples by real-time PCR. The effect of TSA on ERK phosphorylation (p-ERK1/2) in cumulus cells and GDF9 protein level in fully grown oocytes (FGOs) were detected by Western blotting. The expression levels of the ECM genes were significantly decreased $(\mathrm{p}<0.05)$ by TSA treatment while GDF9 expression did not response to TSA $(\mathrm{p}>0.05)$. TSA treatment blocked the activation of ERK1/2 $(\mathrm{p}<0.05)$ and had no significant effect on GDF9 protein expression ( $>0.05)$. Collectively, these results suggested that TSA treatment altered ECM gene expression and blocked ERK1/2 activation to inhibit cumulus expansion in the mouse. (Key Words: Mouse, Cumulus-oocyte Complex, Cumulus Expansion, TSA)
\end{abstract}

\section{INTRODUCTION}

Cumulus expansion is a highly coordinated process that facilitates the release of the oocyte into the abdominal cavity, capture of the oocyte by the oviductal fimbria, and fertilization (Dragovic et al., 2005). Cumulus expansion is a critical physiological process, as impaired expansion leads to sterility (Fulop et al., 2003). Expansion of the mouse cumulus-oocyte complexes (COCs) is critically dependent upon two signaling events: i) stimulation by gonadotropins or epidermal growth factors (EGFs) and ii) paracrine signals secreted by the oocyte, termed cumulus expansion-enabling factors (CEEFs), which act on neighboring cumulus cells, enabling these cells to respond to the aforementioned stimuli (Buccione et al., 1990; Vanderhyden et al., 1990; Dragovic et al., 2007).

GDF9, a member of the transforming growth factor $\beta$ (TGF $\beta$ ) superfamily of protein signaling molecules, shares sequence homology and predicted structural homology with bone morphogenetic proteins (BMPs) (McPherron et al.,

\footnotetext{
* Corresponding Author: Shien Zhu. Fax: +86-10-62731767, E-mail: zhushien@cau.edu.cn

Submitted Feb. 28, 2013; Accepted Apr. 8, 2013; Revised Jun. 3, 2013
}

1993). In rodents, GDF9 is produced primarily in the ovaries and is localized exclusively to oocytes in growing follicles (Hayashi et al., 1999). Moreover, GDF9 was the first oocyte-specific factor shown to be essential for cumulus expansion (Elvin et al., 1999). Deletion of GDF9 results in female results in sterility due to impair follicular development. In these mice, all follicles are arrested at the the primary follicle stage (Dong et al., 1996). GDF9 represents one of several key CEEFs that serve as key mediators that promoting cumulus expansion in the mouse (Gui et al., 2005).

Cumulus expansion stimulated by a ligand (FSH or EGF) and CEEFs is associated with elevated levels of extracellular matrix (ECM) genes (Has2, Ptgs2, Ptx3, and Tnfaip6) in cumulus cells (Ochsner et al., 2003; Su et al., 2003; Salustri et al., 2004). Hyaluronan synthase 2 (HAS2) is the key enzyme required for the production of hyaluronic acid, a non-sulfated glycosaminoglycan secreted by cumulus cells. Non-sulfated glyosaminoglacycan is a fundamental component of the cumulus matrix (Camaioni et al., 1993; Chen et al., 1993). Prostaglandin synthase 2 (PTGS2, also known as COX2, cyclooxygenase 2), the product of cumulus cells and granulosa cells, is required for 
maximum cumulus expansion and ovulation (Lim et al., 1997). Tumor necrosis factor-induced protein 6 (TNFAIP6, also known as TSG6), is a secreted protein that binds hyaluronic acid and inter- $\alpha$ trypsin inhibitor (ITI), which is a serum-derived protein important for matrix formation. TSG6 binding cross-links ITI heavy chains to hyaluronic acid (Fulop et al., 2003; Mukhopadhyay et al., 2004). Pentraxin 3 (PTX3), is also secreted by cumulus cells and acts to stabilize TNFAIP6 protein to maintain the expanded matrix (Salustri et al., 2004; Varani et al., 2002). In addition to extracellular matrix, intracellular signaling cascades play crucial roles in controlling by gonadotropins and growth factors-induced cumulus expansion. For example, mitogenactivated protein kinase activity mediates gonadotropin response in mouse cumulus cells. Inhibition of MEK activation using pharmacologically inhibitor U0126 blocks GDF9-induced cumulus expansion and suppress the expression of ECM genes (Su et al., 2002).

Despite of these important findings, our understanding of transcriptional regulation of gene expression in cumulus cells during oocyte maturation remains limited. In general, histone hyper-acetylation is associated with transcriptional activation, and in contrast, histone hypo-acetylation is indicative of transcriptional repression (Barter et al., 2010). However, in large-scale gene studies, a significant number of genes are down-regulated when HDAC activity is inhibited (Xu et al., 2007). Trichostatin A (TSA), a fermentation product of Streptomyces, is widely used as a non-selective general histone deacetylase (HDAC) inhibitor to study gene regulation in animal cells (Tsuji et al., 1976). For example, TSA and sodium butyrate $(\mathrm{NaB})$ treatment cause reductions in the mRNA levels of the $c d k l$ gene (Saunders et al., 1999). Furthermore, TSA represses $\beta$-casein expression in mammary epithelial cells (Pujuguet et al., 2001), TSA represses the cyclins B1 and A (Nair et al., 2001), and TSA inhibits mouse mammary tumor virus (MMTV) transcription (Mulholland et al., 2003). Based on previous reports, we hypothesized that inhibition of histone acetylation with TSA may inhibit cumulus expansion and change expression of cumulus expansion-related genes. To verify this hypothesis, we investigated the effects of TSA on cumulus expansion during oocyte maturation by assaying the expression of related genes and proteins.

\section{MATERIALS AND METHODS}

All chemicals and media were purchased from Sigma Chemical Co. (St. Louis, MO) unless otherwise indicated. The animals used in this study were 22-24-d-old Kunming white mice (Academy of Military Medical Sciences, Beijing, China) that were maintained at $20-22^{\circ} \mathrm{C}$ on a $14 \mathrm{~h}(6: 00$ to 20:00) light and $10 \mathrm{~h}$ (20:00 to 6:00) dark schedule. The experimental protocols for handing the mice were in accordance with the guidelines of the Institutional Animal Care and Use Committee of the China Agricultural University.

\section{Cell isolation and culture}

Female mice were injected with $10 \mathrm{IU}$ eCG (Ningbo Hormone Products CO., China) for 46 to $48 \mathrm{~h}$ to stimulate follicular development. COCs and fully grown oocytes (FGOs) were then isolated as previously described (Su et al., 2008). Microsurgical removal of oocytes from the COCs was carried out as previously described (Dragovic et al., 2007). The resulting oocytectomized complex (OOX) consisted of the spherical zona pellucida, surrounded by the cumulus cell mass, but was deprived of the oocyte. The culture medium used for all of the experiments was Waymouth's MB752/1 Medium (Life Technologies, Inc., Grand Island, NY) with $10 \mathrm{ng} / \mathrm{mL}$ epidermal growth factor (EGF), $10 \mu \mathrm{M}$ milrinone, $75 \mathrm{mg} / \mathrm{L}$ penicillin $\mathrm{G}, 50 \mathrm{mg} / \mathrm{L}$ streptomycin sulfate, $0.23 \mathrm{mM}$ pyruvate, and $5 \%$ fetal bovine serum (FBS). All of the cultures were maintained at $37^{\circ} \mathrm{C} 5 \mathrm{CO}_{2}$ in air with maximum humidity. The cells were cultured for various periods of time, according to each experimental design and were then harvested for RNA or protein extraction.

\section{Cumulus expansion experiment}

COCs and OOX cumulus cells+FGOs (two FGOs/ $\mu \mathrm{L}$ of medium) were cultured in a drop of medium covered with mineral oil at a density of one COC or OOX cumulus cell $/ \mu \mathrm{L}$ of medium in a $35-\mathrm{mm}$ diameter plastic Petri dish (Nuclon, Rochester, NY) for $15 \mathrm{~h}$. TSA was added to the culture medium in the treatment group. The concentration of TSA $(100 \mathrm{nM})$ was determined as described previously (Suo et al., 2010). The FGOs and OOX were pretreated with $100 \mathrm{nM}$ TSA for $30 \mathrm{~min}$ or $4 \mathrm{~h}$ and were then cocultured with the OOX and FGOs for $15 \mathrm{~h}$, respectively. The experimental design is shown in Table 1. The degree of cumulus expansion was scored after $15 \mathrm{~h}$ of culture according to a subjective scale ranging from 0 (no expansion) to 4 (complete expansion), and a cumulus expansion index (CEI) was calculated (range, 0 to 4.00), as described previously (Fagbohun et al., 1990;

Table 1. Experimental design

\begin{tabular}{ll}
\hline Group & \multicolumn{1}{c}{ Treatment } \\
\hline I & COC \\
II & COC+TSA \\
III & OOX+FGOs \\
IV & OOX+FGOs+TSA \\
V & (FGOs+TSA 30 min)+OOX \\
VI & (OOX+TSA 30 min)+FGOs \\
VII & (FGOs+TSA 4 h)+OOX \\
VIII & (OOX+TSA 4 h)+FGOs \\
\hline
\end{tabular}


Table 2. Primer sequences

\begin{tabular}{lll}
\hline Gene symbol & \multicolumn{1}{c}{ Forward } & Reverse \\
\hline Has 2 & CGAGTCTATGAGCAGGAGCTG & GTGATTCCGAGGAGGAGAGACA \\
Ptgs 2 & CCCTTCCTCCCGTAGCAGAT & TGAACTCTCTCCGTAGAAGAACCTTT \\
Ptx3 & TTGCTGAGACCTCGGATGAC & GCGAGTTCTCCAGCATGATGA \\
Tnfaip6 & ATACAAGCTCACCTACGCCGA & ATCCATCCAGCAGCACAGACAT \\
GDF9 & GCTCTATAAGACGTATGCTACC & CAGAGTGTATAGCAAGACCGAT \\
Rpl19 & TCAGGCTACAGAAGAGGCTTGC & ATCAGCCCATCCTTGATCAGC \\
\hline
\end{tabular}

Vanderhyden et al., 1990).

\section{cDNA preparation and real-time PCR analysis}

Total RNA was isolated and was treated with DNase I to eliminate the DNA contamination. cDNA was synthesized using an Ambion Cells-to-cDNA II kit (Life Technologies, Inc., Grand Island, NY) with MMLV reverse transcriptase and random hexamers, following the manufacturer's instructions. Real-time PCR analyses were conducted as described previously (Su et al., 2008) to quantify the mRNA levels of Has2, Ptx3, Ptgs2, Tnfaip6, and GDF9 and the housekeeping gene Rpl19 (internal control). The primer sequences for Has2, Ptx3, Ptgs2, Tnfaip6, GDF9, and Rpl19 are listed in Table 2. Calculation of the relative fold change in the levels of Has2, Ptx3, Ptgs2, Tnfaip6, and $G D F 9$ was performed using the $2^{-\Delta \Delta C t}$ method, as previously described (Su et al., 2007). For each experiment, the levels of Has2, Ptx3, Ptgs2, Tnfaip6, or GDF9 mRNA are presented as relative changes compared to a specific group (internal control) in which the expression level was set at 1. All the experiments were repeated three times, and data were presented as mean \pm SEM.

\section{Western blot}

Protein samples from 100 FGOs or cumulus cells from 50 OOX were prepared, and Western blot analysis was performed as described previously (Su et al., 2001). The phosphorylated forms of MAPK were detected using a monoclonal anti-MAPK activated (diphosphorylated ERK1 and -2) antibody. The secondary antibody used for the detection of the MAPK primary antibody complex was horseradish peroxidase-conjugated goat anti mouse IgG. Proteins on the membrane were visualized using an ECL detection system (Pierce Chemical Co., Rockford, IL). After the initial analysis, the membranes were washed in a stripping buffer (Pierce Chemical Co. Rockford, IL) to remove bound antibodies and were reprobed with a polyclonal anti-MAPK antibody to detect the total amount of MAPK (phosphorylated and unphosphorylated forms). The second antibody used in the reprobing was horseradish peroxidase-conjugated goat anti rabbit IgG (Sigma). The actin primary antibody was a mouse monoclonal antibody (Santa Cruz Biotechnology, Santa Cruz, CA). The GDF-9 primary antibody was a goat polyclonal antibody generated against a synthetic peptide based on the mouse GDF-9 sequence (Santa Cruz Biotechnology, Santa Cruz, CA), and a donkey anti-goat IgG-horseradish peroxidase conjugate (Santa Cruz Biotechnology) was used as the secondary antibody.

\section{Statistical analysis}

All of the experiments were performed independently at least three times. Data were analyzed using one-way ANOVA and Duncan's test for mean differences $(p<0.05)$ in SPSS 17.0. The results are expressed as the mean \pm standard error of the mean (SEM).

\section{RESULTS}

\section{Effect of TSA on cumulus expansion}

As shown in Figure 1, cumulus expansion did not occur in the group treated with $100 \mathrm{nM}$ TSA (Figure 1-I, II). The corresponding CEI of group I (3.93 \pm 0.01$)$ was significantly higher than that of group II $(0.83 \pm 0.04)$ (Figure $1 \mathrm{~A}, \mathrm{p}<0.05)$. TSA treatment inhibited cumulus expansion in the OOX and FGO co-cultured groups (groups III and IV) (Figure 1III, IV). The corresponding CEI of group III (3.84 \pm 0.02$)$ was significantly higher than that of group IV $(0.77 \pm 0.03)$ (Figure 1A, p <0.05). The FGOs and OOX were pretreated with $100 \mathrm{nM}$ TSA for $30 \mathrm{~min}$ or $4 \mathrm{~h}$ and were then cocultured with OOX or FGOs, respectively, for $15 \mathrm{~h}$. The CEIs of groups V $(3.1 \pm 0.04)$ and VII $(3.0 \pm 0.04)$ were significantly higher than those of groups VI $(1.87 \pm 0.04)$ and VIII (1.81 \pm 0.03 ) (Figure $1 \mathrm{~A}, \mathrm{p}<0.05)$, indicating that cumulus expansion in groups $\mathrm{V}$ and VII (Figure 1-V, VII) was greater than in groups VI and VIII (Figure 1-VI, VIII).

\section{Effect of TSA on ECM (Has2, Ptgs2, Ptx3, and Tnfaip6) and $G D F 9$ gene expression}

The mRNA levels of the cumulus expansion-related genes Has2, Ptgs2, Ptx3, and Tnfaip6 and the expression level of GDF9 were detected. As shown in Figrue 2A to D, the mRNA levels of Has2, Ptgs2, Ptx3, and Tnfaip6 in groups II, IV, VI, and VIII significantly decreased compared to groups I, III, V, and VII, respectively $(\mathrm{p}<0.05)$. The TSA treatment had no significant effect on GDF9 expression (Figure 2E p>0.05). 

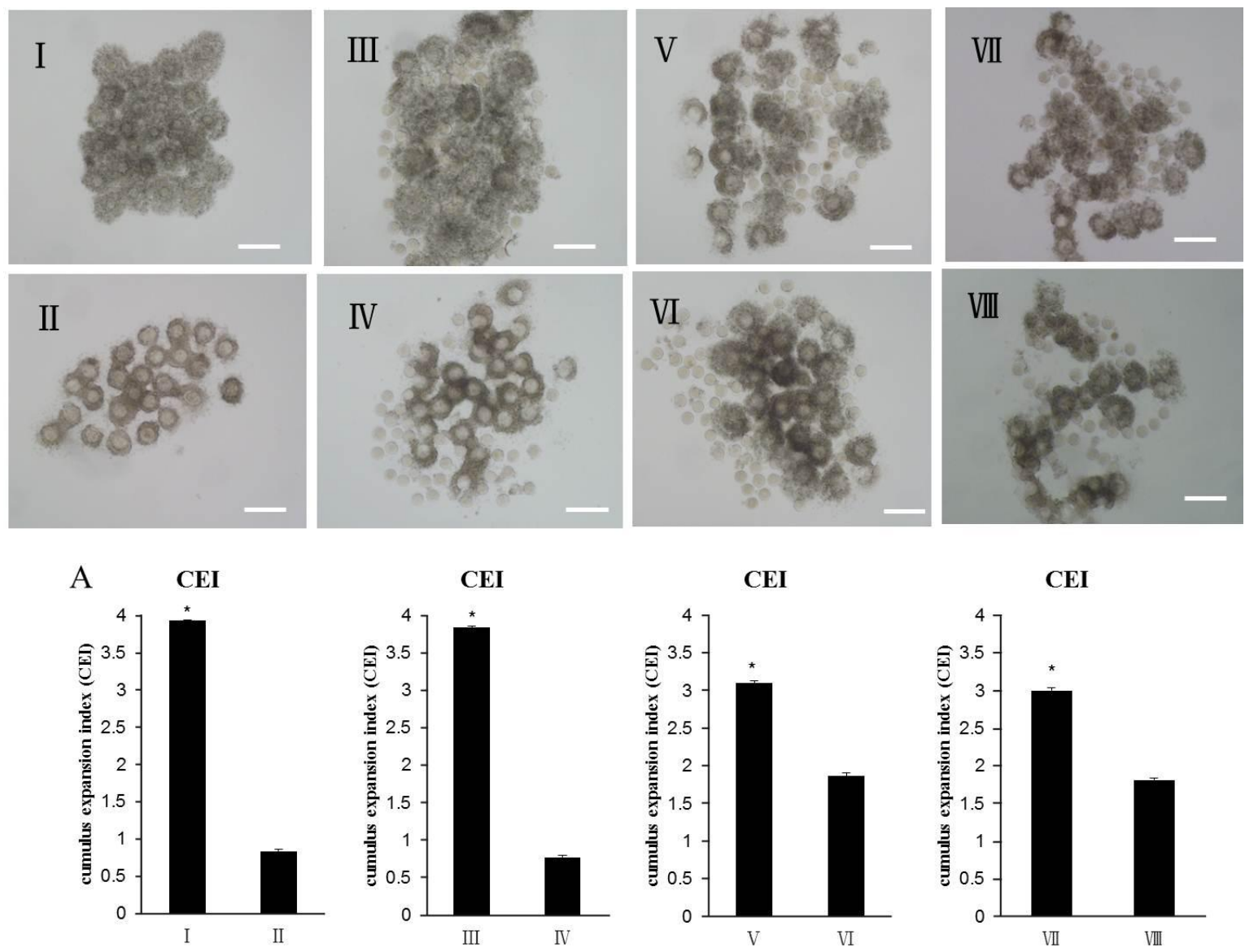

Figure 1. Effect of TSA on cumulus expansion. The COCs and OOX cumulus cells+FGOs (two FGOs/ $\mu \mathrm{L}$ of medium) were cultured in a drop of medium covered with mineral oil at a density of 1 COC or OOX cumulus cell/ $\mu \mathrm{L}$ of medium for $15 \mathrm{~h}$. TSA (100 nM) was added to the culture medium in the treatment group. The FGOs and OOX were pretreated with $100 \mathrm{nM}$ TSA for $30 \mathrm{~min}$ or $4 \mathrm{~h}$ and were then cocultured with OOX and FGOs, respectively, for $15 \mathrm{~h}$, respectively. The CEI of each group was calculated at the end of the culture period (15 h). Figure 1-I to VIII represent Group I to Group VIII (for details of the experiment design see Table 1). Figure 1A represents the CEI of each group. The results represent the mean \pm SEM. from three experiments. An asterisk represents a significant difference ( $<<0.05$ ). Scale bars indicate $200 \mu \mathrm{m}$.

\section{Effect of TSA on the activation of ERK1/2 and on GDF9 protein expression}

In previous reports, ERK activity (p-ERK1/2) in cumulus cells was detected at 30 min and maximal levels were observed at $4 \mathrm{~h}$ (Su et al., 2002). Hence, we detected ERK activity in cumulus cells that received TSA treatment for either $30 \mathrm{~min}$ or $4 \mathrm{~h}$, and we assayed GDF9 expression in the FGOs. As shown in Figure 3A, TSA significantly blocked the activation of ERK $1 / 2$ in the cumulus cells $(p<0.05)$. The TSA treatment had no significant effect on GDF9 protein expression (Figure 3B p>0.05).

\section{DISCUSSION}

In the present study, we found that TSA treatment inhibited cumulus expansion. Cumulus expansion is a highly coordinated process that occurs a few hours prior to ovulation and involves the production of a complex extracellular matrix (ECM) (Fulop et al., 2003). During
COCs in vitro maturation, the oocytes secret one or more factors to promote cumulus granulosa cell proliferation and modulate extracellular matrix components (Vanderhyden et al., 1992). Activation of several key ECM genes in cumulus cells plays crucial roles regulating gonadotropin-dependent cumulus expansion including Has2, Ptgs2 (also known as Cox2), Ptx3, and Tnfaip6 (Fulop et al., 2003; Lim et al., 1997; Su et al., 2003). We determined the expression levels of the ECM genes after TSA treatment and found that TSA significantly reduced the mRNA levels of the cumulus expansion related genes. This phenomenon may result from the TSA-induced blocked activation of ERK1/2. Because the ERK1/2 activity in cumulus cells is essential for gonadotropin-induced cumulus expansion in the mouse. The specific MEK inhibitor U0126 can block GDF9induced cumulus expansion and suppress the expression of ECM genes ( $\mathrm{Su}$ et al., 2002). GDF9 is a specific oocytesecreted factor and a member of the transforming growth factor $\beta$ (TGF $\beta$ ) superfamily (McPherron et al., 1993; 

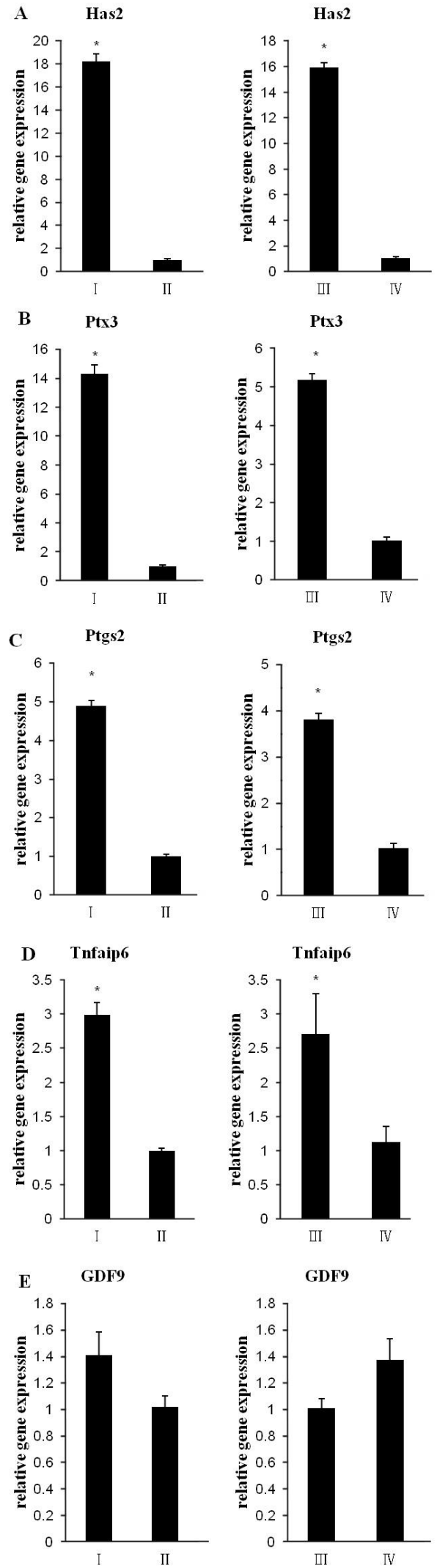

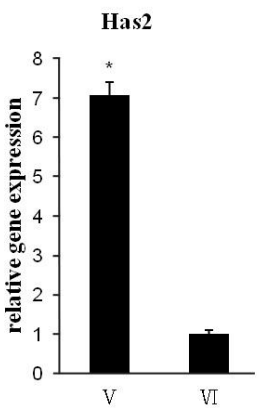

Ptx3

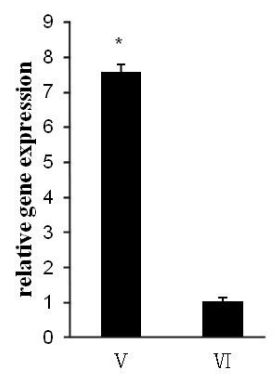

Ptgs2
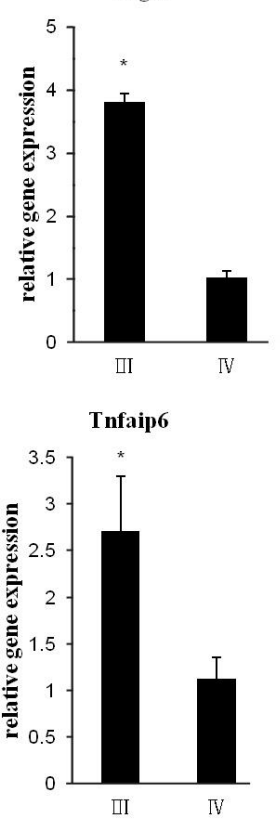

GDF9
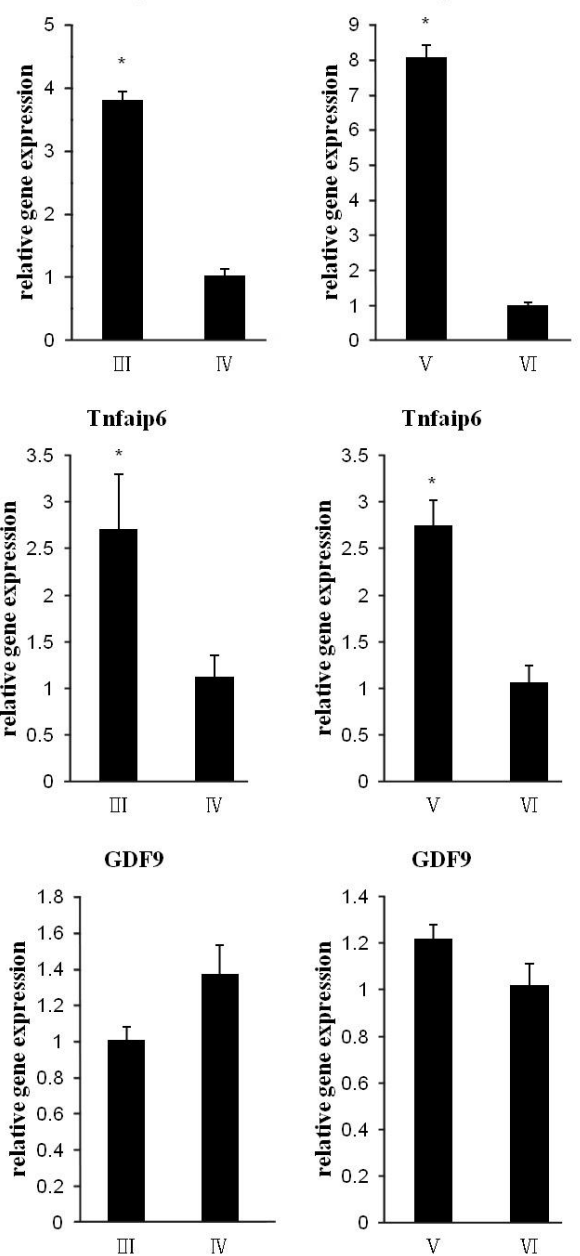

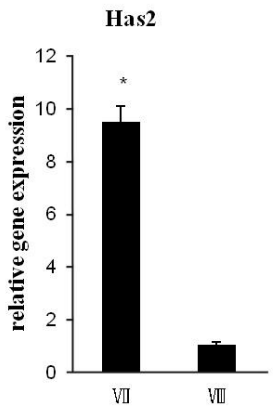

Ptx3

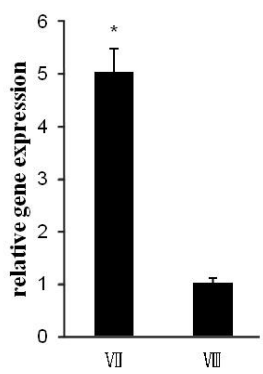

Ptgs2
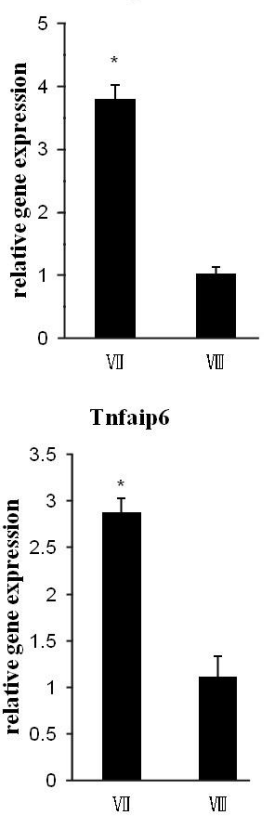

GDF9

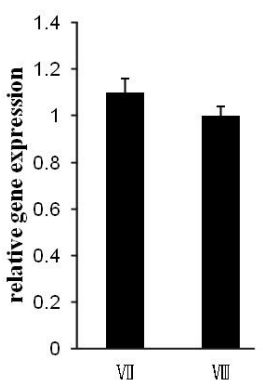

Figure 2. Effect of TSA on ECM (Has2, Ptgs2, Ptx3, and Tnfaip6) and GDF9 gene expression. Steady-state levels of (A) Has2, (B) Ptx3, (C) Ptgs2, (D) Tnfaip6, and (E) GDF9 expression in Group I to Group VIII were detected at $12 \mathrm{~h}$. The results represent the mean \pm SEM from three experiments. An asterisk represents a significant difference $(\mathrm{p}<0.05)$. 
A
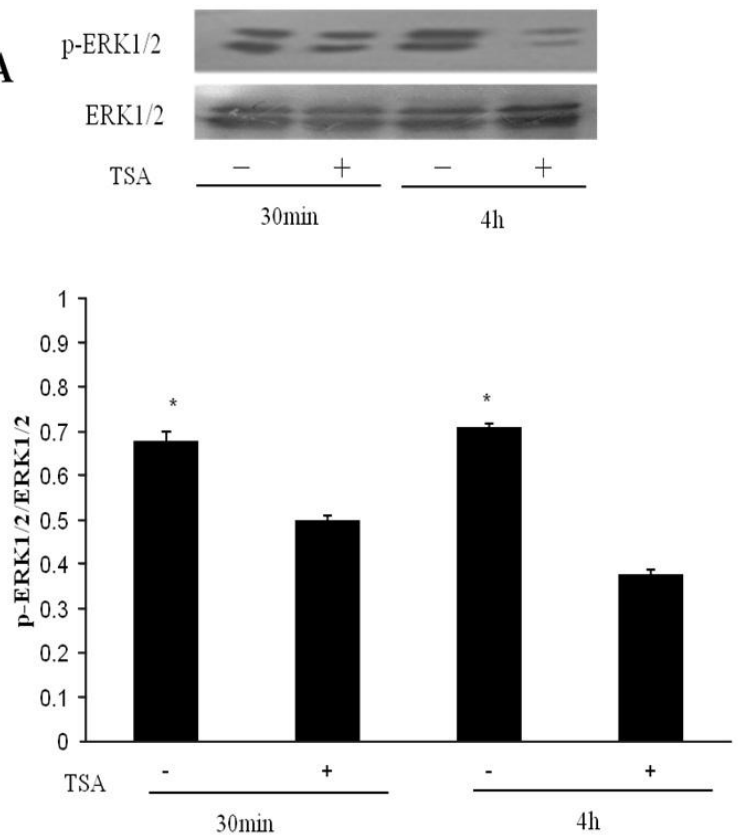

B
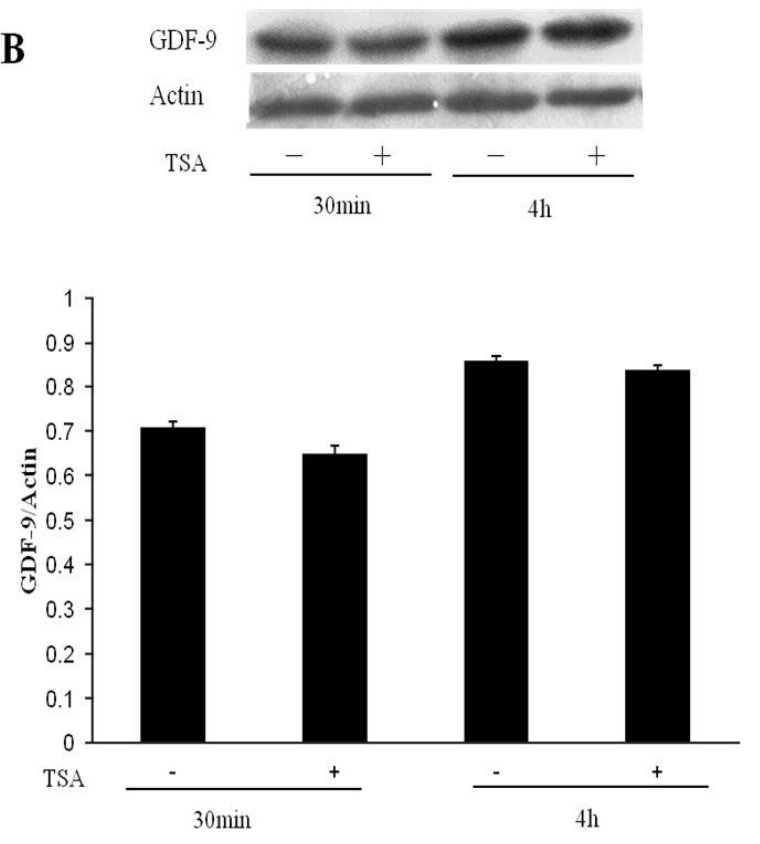

Figure 3. Effect of TSA on the activation of ERK1/2 and on GDF9 protein expression. The OOX cumulus cells+FGOs (two FGOs/ $\mu \mathrm{L}$ of medium) were cultured for $30 \mathrm{~min}$ or $4 \mathrm{~h}$, and then the proteins were isolated for sample preparation. Proteins were separated by SDSPAGE gel electrophoresis, transferred to Protran nitrocellulose membranes and probed with specific antibodies. (A) Western blot analysis of p-ERK1/2. (B) Western blot analysis of GDF9. The results represent the mean \pm SEM from three experiments. An asterisk represents a significant difference $(\mathrm{p}<0.05)$.

Hayashi et al., 1999). Additionally, TSA can inhibit the expression of tissue inhibitor of metalloproteinases-1 (Timp-1) in the presence of TGF $\beta$ (Barter et al., 2010), as the metalloproteinases (TIMPs) safeguard ECM integrity by virtue of their ability to inhibit the matrix metalloproteinases (MMPs) (Baker et al., 2002). Hence, another possible reason for the reduction of the mRNAs of ECM genes was that TSA inhibited Timp-1 expression in the presence of TGF $\beta$, leading to a loss of the ability to safeguard ECM integrity thereby blocking cumulus expansion.

The cumulus-oocyte complexes (COCs) were composed of fully grown oocytes (FGOs) and their surrounding cumulus cells. To determine which components were under the influence of TSA, microsurgical removal of the oocyte from the COC (OOX) was performed following a microsurgical protocol. The FGOs and OOX were pretreated with $100 \mathrm{nM}$ TSA for $30 \mathrm{~min}$ or $4 \mathrm{~h}$ and were then co-cultured with either OOX or FGOs, respectively, for 15 h. Cumulus expansion was inhibited (Figure 1-VI, VIII), and ECM gene expression was significantly reduced (Figure 2A to D) when the OOX were pretreated with TSA for $30 \mathrm{~min}$ or $4 \mathrm{~h}$. ERK1/2 activity in the cumulus cells ( $\mathrm{Su}$ et al., 2002) and the presence of the specific oocyte-secreted factor GDF9 (Elvin et al., 1999) are essential for cumulus expansion. We further explored the activity of ERK1/2 and GDF9 protein expression and found that TSA significantly blocked the activation of ERK1/2 (Figure 3A, p<0.05). The results were consistent with the previously finding that HDAC inhibitors (TSA) reduce the levels of TGF- $\beta$ induced ERK1/2 phosphorylation (p-ERK1/2) (Barter et al., 2010). Hence, in the presence of TGF- $\beta$, the addition of TSA to the culture medium led to a reduction in $\mathrm{p}-\mathrm{ERK} 1 / 2$ levels in the cumulus cells, which most likely inhibited cumulus expansion. The effects of HDAC inhibition on the ERK pathways may be due to enhanced phosphatase activity or reduced activation (Barter et al., 2010). Because recombinant HDAC6 binds directly to the protein phosphatase 1 (PP1) catalytic subunit, TSA disrupts endogenous HDAC6-PP1 complexes and activates PP1 (Brush et al., 2004). TSA treatment had no effect on GDF9 gene and protein expression. Collectively, it seemed that the inhibitory effect of TSA on cumulus expansion was mainly due to its effect on the cumulus cells.

In conclusion, TSA treatment inhibited mouse cumulus cells expansion probably though abolishing ERK1/2 activation and reducing the expressiong of several key ECM genes.

\section{ACKNOWLEDGEMENTS}

This work was supported by the National Natural Science Foundation Project of China (No. 30972102). We thank Dr. Guangbin Zhou, Dr. Qien Yang and NPG language editing for proofreading the manuscript. 


\section{REFERENCES}

Baker, A. H., D. R. Edwards, and G. Murphy. 2002. Metalloproteinase inhibitors: Biological actions and therapeutic opportunities. J. Cell Sci. 115:3719-3727.

Barter, M. J., L. Pybus, G. J. Litherland, A. D. Rowan, I. M. Clark, D. R. Edwards, T. E. Cawston, and D. A. Young. 2010. Hdacmediated control of erk- and pi3k-dependent tgf-beta-induced extracellular matrix-regulating genes. Matrix Biol. 29:602-612.

Brush, M. H., A. Guardiola, J. H. Connor, T. P. Yao, and S. Shenolikar. 2004. Deactylase inhibitors disrupt cellular complexes containing protein phosphatases and deacetylases. J. Biol. Chem. 279:7685-7691.

Buccione, R., B. C. Vanderhyden, P. J. Caron, and J. J. Eppig. 1990. Fsh-induced expansion of the mouse cumulus oophorus in vitro is dependent upon a specific factor(s) secreted by the oocyte. Dev. Biol. 138:16-25.

Camaioni, A., V. C. Hascall, M. Yanagishita, and A. Salustri. 1993. Effects of exogenous hyaluronic acid and serum on matrix organization and stability in the mouse cumulus cell-oocyte complex. J. Biol. Chem. 268:20473-20481.

Chen, L., P. T. Russell, and W. J. Larsen. 1993. Functional significance of cumulus expansion in the mouse: Roles for the preovulatory synthesis of hyaluronic acid within the cumulus mass. Mol. Reprod. Dev. 34:87-93.

Dong, J., D. F. Albertini, K. Nishimori, T. R. Kumar, N. Lu, and M. M. Matzuk. 1996. Growth differentiation factor-9 is required during early ovarian folliculogenesis. Nature 383:531-535.

Dragovic, R. A., L. J. Ritter, S. J. Schulz, F. Amato, D. T. Armstrong, and R. B. Gilchrist. 2005. Role of oocyte-secreted growth differentiation factor 9 in the regulation of mouse cumulus expansion. Endocrinology 146:2798-2806.

Dragovic, R. A., L. J. Ritter, S. J. Schulz, F. Amato, J. G. Thompson, D. T. Armstrong, and R. B. Gilchrist. 2007. Oocyte-secreted factor activation of smad $2 / 3$ signaling enables initiation of mouse cumulus cell expansion. Biol. Reprod. 76:848-857.

Elvin, J. A., A. T. Clark, P. Wang, N. M. Wolfman, and M. M. Matzuk. 1999. Paracrine actions of growth differentiation factor-9 in the mammalian ovary. Mol. Endocrinol. 13:10351048.

Fagbohun, C. F. and S. M. Downs. 1990. Maturation of the mouse oocyte-cumulus cell complex: Stimulation by lectins. Biol. Reprod. 42:413-423.

Fulop, C., S. Szanto, D. Mukhopadhyay, T. Bardos, R. V. Kamath, M. S. Rugg, A. J. Day, A. Salustri, V. C. Hascall, T. T. Glant, and K. Mikecz. 2003. Impaired cumulus mucification and female sterility in tumor necrosis factor-induced protein-6 deficient mice. Development 130:2253-2261.

Gui, L. M. and I. M. Joyce. 2005. Rna interference evidence that growth differentiation factor-9 mediates oocyte regulation of cumulus expansion in mice. Biol. Reprod. 72:195-199.

Hayashi, M., E. A. McGee, G. Min, C. Klein, U. M. Rose, M. van Duin, and A. J. Hsueh. 1999. Recombinant growth differentiation factor-9 (gdf-9) enhances growth and differentiation of cultured early ovarian follicles. Endocrinology 140:1236-1244.

Lim, H., B. C. Paria, S. K. Das, J. E. Dinchuk, R. Langenbach, J. M. Trzaskos, and S. K. Dey. 1997. Multiple female reproductive failures in cyclooxygenase 2-deficient mice. Cell.
91:197-208.

McPherron, A. C. and S. J. Lee. 1993. Gdf-3 and gdf-9: Two new members of the transforming growth factor-beta superfamily containing a novel pattern of cysteines. J. Biol. Chem. 268:3444-3449.

Mukhopadhyay, D., A. Asari, M. S. Rugg, A. J. Day, and C. Fulop. 2004. Specificity of the tumor necrosis factor-induced protein 6-mediated heavy chain transfer from inter-alpha-trypsin inhibitor to hyaluronan: Implications for the assembly of the cumulus extracellular matrix. J. Biol. Chem. 279:11119-11128.

Mulholland, N. M., E. Soeth, and C. L. Smith. 2003. Inhibition of mmtv transcription by hdac inhibitors occurs independent of changes in chromatin remodeling and increased histone acetylation. Oncogene 22:4807-4818.

Nair, A. R., L. J. Boersma, L. Schiltz, M. A. Chaudhry, and R. J. Muschel. 2001. Paradoxical effects of trichostatin a: Inhibition of nf-y-associated histone acetyltransferase activity, phosphorylation of hgen 5 and downregulation of cyclin a and b1 mrna. Cancer Lett. 166:55-64.

Ochsner, S. A., A. J. Day, M. S. Rugg, R. M. Breyer, R. H. Gomer, and J. S. Richards. 2003. Disrupted function of tumor necrosis factor-alpha-stimulated gene 6 blocks cumulus cell-oocyte complex expansion. Endocrinology 144:4376-4384.

Pujuguet, P., D. Radisky, D. Levy, C. Lacza, and M. J. Bissell. 2001. Trichostatin a inhibits beta-casein expression in mammary epithelial cells. J. Cell Biochem. 83:660-670.

Salustri, A., C. Garlanda, E. Hirsch, M. De Acetis, A. Maccagno, B. Bottazzi, A. Doni, A. Bastone, G. Mantovani, P. P. Beck, G. Salvatori, D. J. Mahoney, A. J. Day, G. Siracusa, L. Romani, and A. Mantovani. 2004. Ptx3 plays a key role in the organization of the cumulus oophorus extracellular matrix and in in vivo fertilization. Development 131:1577-1586.

Saunders, N., A. Dicker, C. Popa, S. Jones, and A. Dahler. 1999. Histone deacetylase inhibitors as potential anti-skin cancer agents. Cancer Res. 59:399-404.

Su, Y. Q., J. M. Denegre, K. Wigglesworth, F. L. Pendola, M. J. O'Brien, and J. J. Eppig. 2003. Oocyte-dependent activation of mitogen-activated protein kinase (erk1/2) in cumulus cells is required for the maturation of the mouse oocyte-cumulus cell complex. Dev. Biol. 263:126-138.

Su, Y. Q., S. Rubinstein, A. Luria, Y. Lax, and H. Breitbart. 2001. Involvement of mek-mitogen-activated protein kinase pathway in follicle-stimulating hormone-induced but not spontaneous meiotic resumption of mouse oocytes. Biol. Reprod. 65:358365.

Su, Y. Q., K. Sugiura, K. Wigglesworth, M. J. O'Brien, J. P. Affourtit, S. A. Pangas, M. M. Matzuk, and J. J. Eppig. 2008. Oocyte regulation of metabolic cooperativity between mouse cumulus cells and oocytes: Bmp15 and gdf9 control cholesterol biosynthesis in cumulus cells. Development 135:111-121

Su, Y. Q., K. Sugiura, Y. Woo, K. Wigglesworth, S. Kamdar, J. Affourtit, and J. J. Eppig. 2007. Selective degradation of transcripts during meiotic maturation of mouse oocytes. Dev. Biol. 302:104-117.

Su, Y. Q., K. Wigglesworth, F. L. Pendola, M. J. O'Brien, and J. J. Eppig. 2002. Mitogen-activated protein kinase activity in cumulus cells is essential for gonadotropin-induced oocyte meiotic resumption and cumulus expansion in the mouse. Endocrinology 143:2221-2232. 
Suo, L., Q. G. Meng, Y. Pei, C. L. Yan, X. W. Fu, T. D. Bunch, and S. E. Zhu. 2010. Changes in acetylation on lysine 12 of histone h4 (ach4k12) of murine oocytes during maternal aging may affect fertilization and subsequent embryo development. Fertil. Steril. 93:945-951.

Tsuji, N., M. Kobayashi, K. Nagashima, Y. Wakisaka, and K. Koizumi. 1976. A new antifungal antibiotic, trichostatin. J. Antibiot (Tokyo). 29:1-6.

Vanderhyden, B. C., P. J. Caron, R. Buccione, and J. J. Eppig. 1990. Developmental pattern of the secretion of cumulus expansion-enabling factor by mouse oocytes and the role of oocytes in promoting granulosa cell differentiation. Dev. Biol. 140:307-317.
Vanderhyden, B. C., E. E. Telfer, and J. J. Eppig. 1992. Mouse oocytes promote proliferation of granulosa cells from preantral and antral follicles in vitro. Biol. Reprod. 46:1196-1204.

Varani, S., J. A. Elvin, C. Yan, J. DeMayo, F. J. DeMayo, H. F. Horton, M. C. Byrne, and M. M. Matzuk. 2002. Knockout of pentraxin 3, a downstream target of growth differentiation factor-9, causes female subfertility. Mol. Endocrinol. 16:11541167.

Xu, W. S., R. B. Parmigiani, and P. A. Marks. 2007. Histone deacetylase inhibitors: Molecular mechanisms of action. Oncogene 26:5541-5552. 